\title{
Efficiency of Indigenous AMF Species on Growth of Soybean (Glycine max L.) under Varying Levels of Phosphorous in Saline Condition
}

\author{
RC Maggirwar ${ }^{1}$, PW Deotare ${ }^{1}$, SP Khodke ${ }^{2}$ \\ ${ }^{1}$ Mycorrhizal Biotechnology Lab, PG Dept. of Botany, Shri Shivaji College, Amravati, Maharashtra, India \\ ${ }^{2}$ Vinayak Vidnayan Mahavidyalaya, Nandgaon (Kh.) Dist. Amravati, Maharashtra, India
}

\begin{abstract}
The pot experiments were undertaken to study the relative efficiency of dominant AM Fungi (Glomus fasciculatum and Glomus heterosporum) recovered from natural undisturbed saline belt of Purna river sub basin. The pure inoculum of these species were treated individually and as a mixed inocula in combination with phosphoric fertilizers supplied as 25, 50, 75 and $100 \%$ (mg/kg $P_{2} \mathrm{O}_{5}$ /ha). The influence of AMF inoculation in different levels of 'P' fertilizer on\% colonization, MIE \% and P-uptake were calculated. $P$ level of $75 \%$ was found to be better in compare to $100 \%$ and can be recommended as phosphoric dose for soybean plants.
\end{abstract}

Keywords: AMF, Glycine max, P-uptake, soil salinity

\section{Introduction}

AM (Arbuscular Mycorrhizal) Fungi, are found to be associated with a number of leguminous crop plants (Bagyaraj et al., 1979; Tilak et al., 1987; Vijay kumar and Bhiravamurthy, 1999) and beneficial effects of these fungi in phosphate uptake have been reported by different workers (Islam and Ayaneba, 1980; Reinhard et al., 1994 and Rajeshwari et al., 2001).Most of the work has been focused on phosphate nutrition, because ' $\mathrm{P}$ ' is one of the major plant nutrients. Soybean being a legume, helps in improving the soil fertility, the relative efficiency of different AM isolates on soybean under varying levels of ' P' h a s b e oned rboypRaverkar and Tilak (1988); Kabirun and Widada (1994) and established that effect of AM fungal inoculation on soybean depends on the AM species as well as on the soil where the soybean is grown. Phosphorus is one of the most least available macronutrient in the soil of Vidarbha region and its unavailability is one of the major growth limiting factors for plants in many natural and artificial ecosystems. The present study elucidated the relative influence of indigenous AM fungi and different phosphoric fertilizer doses on soybean under saline conditions of soil. In response to continual 'P' deficiency, plants bound to adopt many mechanisms for ' $\mathrm{P}$ ' uptake and sustainability (Singh and Jamaluddin, 2008).

\section{Materials and Methods}

The dominant AMF spores of Glomus species (Glomus fasciculatum (Thaxter) Gerdemann \&Trappe emend. Walker and Koske and Glomus heterosporum Smith \& Schenck) were isolated from the rhizosphere soils of natural ecosystem of Purna river saline tract of Amravati District. The isolation of AM spores was carried out by the wet-siewing and decanting technique (Gerdemann and Nicolson, 1963) and the isolated spores were identified on the basis of their morphological characters given in the identification manual of AM fungi (Schenk and Perez, 1990) and key of Mortan and Benny (1990).AMF spores of the most dominant species were purified and multiplied by following funnel technique (Mertz et al.,1979). The pure culture of isolated AM fungi was used for inoculation for Glycine max.

\section{Experimental Set Up}

A pot experiment was set up with sterilized saline clayey loam soil brought from village Nanded (Khurd) located in saline belt of Purna river sub basin. The experimental soil used were having $\mathrm{pH}$ 8.2, $\mathrm{Ec}_{2} \quad 0.28 \mathrm{dsm}^{-1}$, electrical conductivity $1.69 \mathrm{dsm}^{-1}$, nitrogen (84.2 kg/ha), phosphorus (6.7 kg/ha)potassium (441 kg/ha) Org. carbon $0.219 \%$. The isolated pure inoculums of Glomus fasciculatum and Glomus heterosporum along with root bits of maize plants were mixed equally in pot soils (1:1 soil+ sand) as $60 \mathrm{~g}$ of inoculums individually and in mixed combinations. The soil was also supplemented with single super phosphate dose of $\mathrm{P}_{2} \mathrm{O}_{5}$ in different quantities as $25,50,75$ and $100 \%$. The phosphoric fertilizer doses were calculated as per the standard recommended dose per hector for soybean.

The sterilized five seeds of soybean were sown in each pot and irrigated with deionized sterilized water regularly. Percent root colonization, MIE \%, spore count $/ 100 \mathrm{~g}$ of soil and P-uptake of soybean was recorded after every 15, 30 and 45 days of sowing. The grid-line intersect method was adopted for \% root colonization (Giovannetti and Mosse, 1980). The mycorrhizal inoculation effect (MIE) on test crop plant was calculated by the formula given by Bagyaraj et al.(1988) for growth improvement brought about by mycorrhizal inoculation. The total P-uptake by uninoculated and inoculated plants were calculated after experiment by Vando molybdate phosphoric yellow colour method given by Jakson(1967).

\section{Results and Discussion}

Mycorrhizal plants produced higher root colonization at all levels of phosphate than uninoculated control plants. A wide variation was observed in the rate of the root colonization by two AM species at different levels of phosphate. 


\section{International Journal of Science and Research (IJSR) \\ ISSN (Online): 2319-7064 \\ Index Copernicus Value (2013): 6.14 | Impact Factor (2014): 5.611}

Percent Colonization. The microscopic examination of the root samples showed colonization in roots of soybean plants inoculated with mycorrhizal fungi. The plants inoculated with mixed inocula at P 75\% level and LFSC (Glomus fasciculatum) at P 75\% level exhibited highest \% colonization in compare to other P-levels while the \% colonization was found to be inhibited at higher levels of phosphorus (Table-1).Interaction effect between $\mathrm{P}$ levels and $\mathrm{AM}$ isolates differed significantly in influencing \% colonization of root(Table 1A) Neither extra matrical hyphae nor spore was recovered from the non mycorrhizal control plants (because it was planted in sterile soil sand mixture without inoculum). The root colonization by two AMF species namely Glomus fasciculatum and Glomus heterosporum was inhibited at higher levels of phosphates similar observations were recorded by Raverkar and tilak (1988) with G.fasciculatum and Acaulospora sp.

MIE \%.The results are presented in Table-1. There was linear increase in MIE \% with successive increase in levels of phosphorus from 0 to $75 \%$. Application of $75 \% \mathrm{P}_{2} \mathrm{O}_{5}$ recorded highest MIE \% in Glycine max i.e. $55.40 \%$ and $60.90 \%$ at 30 and 45 days after sowing respectively, which was significantly more than other P-levels. Interaction effects between phosphorus levels and AMF isolates on MIE \% of Glycine max are presented in Table 2A.The results proved that mixed inocula of two AMF isolates gave more consistent results and found to be more beneficial. Similar type of observations have been recorded by Daft and Hogarth (1983) and Mehrotra and Baijal (1995).

P- uptake. Mycorrhizal association can enhance the uptake of ' $\mathrm{P}$ ' was earlier reported by Plenchette et al.,1983 and Bolant,1991. The studies on the effect of P-uptake and plant growth were also carried out in different plant species by Prasad et al., 2000; Rajeshwari et al., 2001. In the present findings dual inocula recorded $8.90 \mathrm{mg} / \mathrm{plant}$ phosphorus, this was found significantly superior than other single AMF islolates at 45 days after sowing. Application of $\mathrm{P}_{2} \mathrm{O}_{5}$ at $75 \%$ recorded highest ' $\mathrm{P}$ ' uptake i.e. $9.36 \mathrm{mg} /$ plant which were found significantly more than 100, 50 and $25 \% \mathrm{P}_{2} \mathrm{O}_{5}$. The interaction effect of $75 \%$ $\mathrm{P}_{2} \mathrm{O}_{5}$ with dual inocula also recorded higher uptake of ' $\mathrm{P}$ ' i.e.12.68 mg/plant which was significantly more than all other treatments (Table-2). Improved plant phosphorus uptake by AM inoculation in phosphorus deficient soil has been reported earlier by Marschner and Dell, 1994; Neeraj and Anju Chavan, 2006. Fathima et al.,2000 and Yao et al., 2001 and concluded that AMF species are responsible for more ' $\mathrm{P}$ ' uptake than non-mycorrhizal plants. The present findings are in acquiescence with the conclusion made by earlier researchers. The highest level $(100 \%)$ of ' $\mathrm{P}$ ' proved to be inhibitory in P-uptake for G.max. The similar observations were earlier made by Krishna and Bagyaraj (1982) with $200 \%$ of 'P' and Raverkar and Tilak (1988) at $100 \mathrm{~kg} \mathrm{P}_{2} \mathrm{O}_{5} / \mathrm{ha}$.

The possibility of inoculating G.max with native dominant isolates of AMF can tremendously improve the prospects of successfully exploiting AMF for better yield of legumes, especially those growing in a low input system where concentration of soil phosphate pool is likely to be lower. Hence, these AMF species can be utilized as a bio fertilizer and $25 \%$ of ' $P$ ' fertilizer can be saved in the fields of G.max in salinity affected regions.

\section{References}

[1] Bagyaraj DJ, Manjunath, A. and Patil RB. 1979. Interaction between a Vesicular-Arbuscular Mycorrhiza and Rhizobium and their effects on Soybean in the field. New Phytopathologist. 82:141-145.

[2] Bagyaraj DJ, Manjunath A and Govinda Rao YS. 1988. Mycorrhizal inoculation effect on different crops. Journal of soil Biology and Ecology. 8: 98-103.

[3] Bolant NS. 1991. A critical review on the role of mycorrhizal fungi in the uptake of phosphorus by plants. Plant and soil. 134: 189-207.

[4] Daft MJ and Hogarth DG.1983. Competitive interactions amongst four species of Glomus on maize and onion. Trans. Br. Mycol. Soc. 80: 339-345.

[5] Fathima PS, Das, PK and Katiyar RS. 2000. Effect of different levels and sources of ' $\mathrm{P}$ ' on VA-mycorrhizal root colonization and spore load in mulberry (Morusalba.L.) Crop Res. 20(3): 504-508.

[6] Gerdemann JW and Nicolson TH. 1963. Spores of mycorrhizal Endogone species extracted from soil by wetsieving and decanting. Trans. Brit. Mycol. Soc. 46: 235-244.

[7] Giovannetti M and Mosse B. 1980. An evaluation of techniques for measuring VAM infection in roots. New Phytologist 84 : 489-500.

[8] Jackson ML. 1967. Soil chemical analysis, Prentice Hall publication Pvt. Ltd., New Delhi, India pp: 452.

[9] Islam P, Ayanaba A and Sanders FE. 1980. Response of cowpea (Vignaunguiculata) to inoculation with VA mycorrhizal fungi and to rock phosphate fertilization in some un-sterilized Nigerian soils. Plant and soil 54 : 107117.

[10] Kabirun Siti and Widada Jaka, 1994. Response of soybean grown on acid soil to inoculation of vesicular arbuscular mycorrhizal fungi. Proc. of the II ${ }^{\text {nd }}$ Symp. on Bio and Biotech. of myco. And III ${ }^{\text {rd }}$ ACOM.

[11] Krishna KR and Bagyaraj DJ. 1982. Influence of VA mycorrhiza on growth and nutrition of Arachis hypogaea Legume Res. 5: 18-22.

[12] Marchner H. and Dell B. 1994. Nutrient uptake in mycorrhizal symbiosis. Plant and Soil. Vol. 159, 89-102

[13] Mehrotra VS and Baijal U. 1995. Effects of single and mixed inocula of VAM Fungi on the Growth and yield of sunflower (Helianthus annuus L.). The philippine journal of science 124 (2): 183-201.

[14] Mertz SM, Heithavs JJ and Bush RL. 1979: Mass production of endomycorrhizal fungi Gigaspora margarita. Trans. Br. Mycol. Soc. 72:167-169.

[15] Mortan JB and Benny GL.1990: Revised classification of arbuscular mycorrhizal fungi ( zygomycetes) : A new order, Glomales, Two new families, Acaulosporaceae and Gigasporaceae, with an emendation of Glomaceae Mycotaxon 37: 471-491.

[16] Neeraj and Anju Chauhan.2006, Effect of VAM fungi and P-fertilizers on growth and yield of Trigonella-foenum graecum(L.) Mycorrhiza News.18 (1):19-21.

[17] Plenchette C and Fortin JA and Furlam V.1983. Growth responses to several plant species to mycorrhizae in soil mod. (p) fertility. Plant and soil. 70: 199-209.

[18] Prasad,V.Manjunath, G.T.S.Reddy,C.N.2000. Influence of $G$. fasciculatum inoculation on growth and phosphorus uptake in Gladilous sp.Mycorrhiza News 11(4)

[19] Rajeswari E, Latha TKS, Vanangamudi K, Arulmozhi Selvan K and Narayanan R. 2001. Effect of arbuscular 


\section{International Journal of Science and Research (IJSR) \\ ISSN (Online): 2319-7064 \\ Index Copernicus Value (2013): 6.14 | Impact Factor (2014): 5.611}

mycorrhizae and phosphorus on seedling growth of Casurina equisetifolia. Indian phytopath. 54 (1): 85-87.

[20] Raverkar KP and Tilak KVBR. 1988. Relative efficiency of different VAM on soybean (Glycine max) under varying levels of phosphorus. Proc. $1^{\text {st }}$ Acom.

[21] Reinhard S, Weber E, Martin P, Marschner H.1994 Influence of phosphorus supply and light intensity on mycorrhizal response in Pisum-Rhizobium-Glomus symbiosis EXPEA 50:890-896

[22] Schenck NC and Perez Y. 1990. Manual for the identification of VA mycorrhizal Fungi. INVAM, Gainesville, Florida University.

[23] Singh AK and Jamaluddin. 2008. Phosphatase activity in the rhizosphere of medicinal plants inoculated with arbuscular mycorrhizal fungi.Mycorrhiza News 19(4):11-12
[24] Tilak KV, Singh CS and Gaur YD.1987 Nat. Work, Mycor., J.N.U., New Delhi, 40.

[25] Vijaykumar BS and Bhiravamurthy PV.1999: Selection of efficient indigenous local VAM fungi for improving the groundnut crop in semi-arid tropical soils of Anantapur district, Andhra Pradesh. In proceedings of the National Conference on Mycorrhiza. Section 2 (poster): plant growth responses and mycorrhizal dependency, (5-7 March 1999, Bhopal, India).

[26] Yao O, Xiaolin L, Gu F and Christie P. 2001. Mobilization of sparingly soluble inorganic phosphorus by the external mycelium of an arbuscular mycorrhizal fungus. Plant and soil. 230 (2): 279-285

Table 1: Effect of different levels of phosphorus and AM isolate on \% colonization and MIE \% of Glycine max

\begin{tabular}{|c|c|c|c|c|c|}
\hline Treatments & \multicolumn{3}{|c|}{ \% Colonization } & \multicolumn{2}{c|}{ MIE \% } \\
\hline Main factor 'A' & 15 DAS & 30 DAS & 45 DAS & 30 DAS & 31.87 \\
\hline P0 & 25.44 & 32.60 & 55.30 & 19.46 & 33.60 \\
\hline P25 & 29.00 & 41.27 & 55.67 & 47.30 \\
\hline P50 & 26.17 & 44.11 & 61.17 & 45.50 & 52.43 \\
\hline P75 & 36.67 & 52.33 & 71.43 & 55.40 & 60.90 \\
\hline P100 & 27.67 & 51.50 & 63.57 & 36.87 & 49.17 \\
\hline F' test & Sig & Sig & Sig & Sig & Sig \\
\hline SE(M) & 3.60 & 5.38 & 1.90 & 0.48 & 0.54 \\
\hline CD (P=0.05) & 8.31 & 12.43 & 4.38 & 1.12 & 1.24 \\
\hline Sub factor 'B' & & & & 55.40 & \\
\hline M & 37.07 & 47.50 & 62.40 & 23.63 & 32.86 \\
\hline LHTS & 24.60 & 41.40 & 54.06 & 35.46 & 49.88 \\
\hline LFSC & 25.30 & 44.19 & 67.82 & Sig & Sig \\
\hline F' test & Sig & Sig & Sig & 0.27 & 0.33 \\
\hline SE(M) & 2.56 & 3.77 & 1.70 & 3.57 & 0.68 \\
\hline
\end{tabular}

(LHTSGlomus heterosporum, LFSCGlomus fasciculatum, MIE-Mycorrhizal Inoculation Effect)

Table 1-A: Interaction effect of different levels of phosphorus and AM isolates on \% colonization, MIE \% of Glycine max

\begin{tabular}{|c|c|c|c|c|c|c|c|c|c|c|c|c|c|c|c|}
\hline \multicolumn{10}{|c|}{$\%$ Colonization } & \multicolumn{6}{|c|}{ MIE \% } \\
\hline & \multicolumn{3}{|c|}{$15 \mathrm{DAS}$} & \multicolumn{3}{|c|}{$30 \mathrm{DAS}$} & \multicolumn{3}{|c|}{45 DAS } & \multicolumn{3}{|c|}{ 30DAS } & \multicolumn{3}{|c|}{ 45DAS } \\
\hline Treatment & $\mathrm{M}$ & LHTS & LFSC & $M$ & LHTS & LFSC & $\mathrm{M}$ & LHTS & LFSC & LFSC & $\mathrm{M}$ & LHTS & LFSC & $\mathrm{M}$ & LHTS \\
\hline P0 & 31.33 & 22.00 & 23.00 & 42.00 & 40.00 & 15.79 & 56.00 & 47.00 & 62.90 & 18.70 & 48.00 & -8.33 & & & \\
\hline P25 & 35.00 & 23.00 & 29.00 & 45.00 & 36.00 & 42.80 & 57.00 & 53.00 & 57.00 & 27.00 & 55.10 & 18.70 & & & \\
\hline P50 & 40.00 & 25.00 & 13.51 & 45.00 & 38.00 & 49.33 & 60.00 & 52.50 & 71.00 & 48.00 & 53.50 & 35.00 & & & \\
\hline P75 & 46.00 & 29.00 & 35.00 & 53.00 & 47.00 & 57.00 & 72.00 & 62.80 & 79.50 & 56.60 & 63.80 & 45.80 & & & \\
\hline P100 & 33.00 & 24.00 & 26.00 & 52.00 & 46.00 & 56.00 & 67.00 & 55.00 & 68.70 & 27.00 & 56.60 & 27.00 & & & \\
\hline$F^{\prime}$ test & \multicolumn{3}{|c|}{ Sig } & \multicolumn{3}{|c|}{ Sig } & \multicolumn{3}{|c|}{ Sig } & \multicolumn{3}{|c|}{ Sig } & & & \\
\hline SE(M) & \multicolumn{3}{|c|}{1.48} & \multicolumn{3}{|c|}{2.18} & \multicolumn{3}{|c|}{0.98} & & & & & & \\
\hline $\mathrm{CD}(\mathrm{P}=0.05)$ & \multicolumn{3}{|c|}{3.09} & \multicolumn{3}{|c|}{4.55} & \multicolumn{3}{|c|}{2.05} & & & & & & \\
\hline
\end{tabular}

Table 2: Interaction effect of different levels of phosphorus and AM isolates on $\mathrm{P}$ - uptake of Glycine max

\begin{tabular}{|c|c|c|c|}
\hline Treatment & $M$ & LHTS & LFSC \\
\hline P0 & 6.56 & 2.62 & 4.46 \\
\hline P25 & 8.75 & 3.60 & 7.00 \\
\hline P50 & 9.45 & 5.25 & 8.05 \\
\hline P75 & 12.68 & 6.65 & 8.75 \\
\hline P100 & 7.08 & 4.46 & 4.46 \\
\hline F' test & \multicolumn{3}{|c|}{ Sig } \\
\hline SE(M) 0.18 \\
\hline CD (P=0.05) & \multicolumn{3}{|c}{} \\
\hline
\end{tabular}

